\title{
Effect of Fasting of Ramadan on Infertile Women Undergoing In-Vitro Fertilization/Intracytoplasmic Sperm Injection Cycles: A Prospective Cohort Study
}

\author{
Karim A. Wahba \\ Department of Obstetrics and Gynecology, Ain Shams University Maternity Hospital, Cairo, Egypt \\ Email: karimwahbaobgyn@yahoo.com
}

Received 15 December 2015; accepted 28 February 2016; published 2 March 2016

Copyright (C) 2016 by author and Scientific Research Publishing Inc. This work is licensed under the Creative Commons Attribution International License (CC BY). http://creativecommons.org/licenses/by/4.0/

\section{(c) (i) Open Access}

\section{Abstract}

Objective: To determine the effects of fasting of Ramadan in patients undergoing in-vitro fertilization (IVF)/intracytoplasmic sperm injection (ICSI) cycles. Design: A prospective cohort study conducted during Ramadan. Setting: Ain Shams University IVF centre. Population: Three hundred fasting, infertile women undergoing their first trial of IVF/ICSI and 300 non-fasting matched controls undergoing the same procedure during Ramadan. Methods: Anxiety and depression were measured by the Hospital Anxiety and Depression Scale, at the start of the induction protocol. All the successful pregnant women were followed up until delivery. Main Outcome Measures: The primary outcome measure was the live birth rate. Results: The live birth rate was higher in the fasting group than in the non-fasting group; this was not significant $(43 \%$ vs. $40 \%, P=0.46)$. The fasting group needed higher doses and durations of induction. Embryo quality did not differ between both groups. The pregnancy complication rate among successful cases was higher in the fasting group $(52.9 \%$ vs. $40.4 \%, P=0.03)$; however, the frequencies of anxiety and depression were significantly lower than those in the non-fasting group $(18 \%$ vs. $38 \%, P<0.00001$ and $16 \%$ vs. $37 \%, P<0.00001$, respectively). Conclusion: Fasting during Ramadan does not seem to significantly affect the IVF/ICSI outcome; however, it significantly decreased the anxiety and depression usually associated with these procedures.

\section{Keywords}

Fasting, Ramadan, Infertility, In-Vitro Fertilization, Intracytoplasmic Sperm Injection 


\section{Introduction}

Annual fasting during the holy month of Ramadan is one of the five pillars of Islam. During Ramadan, all ablebodied Muslims abstain from food, fluids, smoking, and oral medication between sunrise and sunset [1].

Ramadan is the ninth month in the Muslim lunar calendar. The daily fast lasts nearly 12 - 19 hours depending on the geographic location and season [2]. Fasting Muslims usually have two meals per day, Iftar at sunset and Sahari (Sohour) before dawn [3].

There are more than 1.5 billion Muslims worldwide, with higher numbers in Asia and Africa. Moreover, many Muslims have permanently immigrated to Europe, North America, and Australia [4].

Many studies have focused on the effects of metabolic changes and health outcomes in various groups of Muslims fasting during Ramadan. Other studies have focused on the effect of fasting during pregnancy and the neonatal outcome. However, no previous studies have determined the effect of fasting in infertile patients undergoing in-vitro fertilization (IVF)/intracytoplasmic sperm injection (ICSI) cycles.

Some Muslim women do not fast during pregnancy in consideration of their children's health, although they do feel guilty because of their religious beliefs. On the other hand, some pregnant women prefer to honour their religious principles despite their consideration of their children's health and fast during pregnancy [5].

The findings of various studies regarding fasting and the outcomes of pregnancy are inconsistent. Some studies reported no significant differences in birth outcomes between fasting and non-fasting mothers [6]-[9], whereas other studies have reported some differences in the anthropometric parameters of neonates [10] [11].

Infertility is a common problem in the general population, with a global prevalence of $9 \%-15 \%$. Because of the great progress in the technical aspects of IVF/ICSI, it has become a very popular method of choice in the management of infertile couples [12].

IVF/ICSI is often described as the most stressful event in the lives of a couple. Some Muslims prefer to postpone these procedures after the holy month in order to concentrate on their faith and worshipping God whereas others prefer to do it during this month because they feel more peaceful and less anxious.

The aim of our study was to determine the effects of fasting of Ramadan in patients undergoing IVF/ICSI cycles during this month.

\section{Patients and Methods}

This was a prospective cohort study carried out in a University IVF centre in Cairo, Egypt during the holy month of Ramadan over a period of three years (20 July to 18 August 2012, 9 July to 7 August 2013, and 29 June to 27 July 2014). The age of all eligible women ranged from 21 to 39 years. The women had either primary or secondary infertility and were undergoing their first trial of IVF/ICSI for various reasons. They also had good ovarian reserve with antimullerian hormone measurements of more than $0.7 \mathrm{ng} / \mathrm{ml}$. Patients with chronic medical diseases were excluded. According to the calculated sample size required, 600 patients were recruited. Group 1 (Cases) included 300 fasting patients and group 2 (the control group) included 300 non-fasting patients. The controls were matched to the fasting group in terms of age, body mass index (BMI), duration of infertility, and reason for infertility.

All patients were thoroughly informed about the study and signed consent forms. The study was approved by the local ethics committee at Ain Shams University Maternity Hospital.

All patients received the long protocol of ovulation induction starting with down-regulation from day 20 of the previous cycle until the start of menses by daily subcutaneous injections of $0.1 \mathrm{mg}$ triptorelin. On day 1 of the cycle, serum estradiol (E2) was measured and a transvaginal ultrasonography was performed. If E2 was less than $50 \mathrm{pg} / \mathrm{mL}$ [13], stimulation was started on day 2 of the cycle with a follicle-stimulating hormone and luteinizing hormone preparation administered intramuscularly with halving the dose of triptorelin. Follow-up was conducted every two to three days at the start of induction and every one to two days thereafter until the end of induction. The size and number of follicles assessed using transvaginal ultrasonography and serial E2 levels were used to tailor the stimulation doses as required. When follicles reached $20 \mathrm{~mm}$ in diameter, 10,000 IU of human chorionic gonadotropin was administered via intramuscular injection and ovum retrieval was performed 34 - 36 hours later.

Embryo transfer was performed on day 3 or 5 following retrieval, depending on the number and quality of embryos. Progesterone tablets and vaginal pessaries were prescribed for luteal phase support. Oral medication was administered between sunset and sunrise in the fasting group.

The primary outcome measure was the live birth rate. Secondary outcomes included the total number of sti- 
mulation days, average daily dose of stimulation medication, total number of oocytes retrieved, number and percentage of MII oocytes retrieved, fertilization rate, embryo quality score, day and number of embryos transferred, pregnancy rate, any pregnancy-related complications, and incidence of hyperstimulation.

Anxiety and depression were measured in both groups at the start of stimulation (day 2 of the cycle) using the Arabic version of the Hospital Anxiety and Depression Scale [14].

For simplicity, embryo scoring was divided into three categories:

A: One or more day 3 embryos with at least eight equal, regular cells and no or minimal fragmentation or one or more day 5 embryos with Gardner grading system [15] of 4AA or higher.

B: One or more day 3 embryos with at least six to eight cells with moderate fragmentation or one or more day 5 embryos with Gardner grading system [15] of 4AB or 4BA.

C: Any day 3 or 5 embryos of poorer quality than that of embryos included in class A or B.

\section{Statistical Analysis}

Considering an average live birth rate of $30 \%$, the sample size was calculated according to a power of $80 \%$, a confidence level of 95\%, an accepted margin of error or 5\%, and a z score of 1.96. A sample size of 600 patients divided into two groups (fasting and non-fasting, 300 in each group) would achieve a power of $80 \%$ to detect a difference in the live birth rate between the group proportions of -0.1000 . The proportion in group 1 (the fasting group) is assumed to be 0.3000 under the null hypothesis and 0.2000 under the alternative hypothesis. The proportion in group 2 (the non-fasting group) is 0.3000 . The statistic test used was the two-sided $\mathrm{Z}$ test with pooled variance. The significance level of the test was targeted at 0.0500 .

Statistical analysis was performed using SPSS statistical package version 13 (SPSS Inc., Chicago, IL, USA). Quantitative data were presented as means with standard deviations and ranges. Qualitative data were presented as numbers and percentages. Categorical data were compared using the chi-squared test. Continuous variables were compared using the Student's t-test. A $P$-value of $<0.05$ was considered statistically significant.

\section{Results}

The mean duration of fasting in group 1 was 26 days (range: 22 to 30 days), as some patients had menses during the month. The mean number of fasting hours was 15 hours and 10 minutes in 2012, 15 hours and 25 minutes in 2013, and 15 hours and 40 minutes in 2014. Demographic data and the duration, aetiology, and type of infertility did not statistically differ between the fasting and non-fasting groups (Table 1).

\begin{tabular}{|c|c|c|c|c|c|c|c|c|c|}
\hline & & \multicolumn{3}{|c|}{ Fasting Group $(\mathrm{N}=300)$} & \multicolumn{3}{|c|}{ Non-Fasting Group $(\mathrm{N}=\mathbf{3 0 0})$} & \multirow{2}{*}{ Student $\mathbf{t}$ test } & \multirow{2}{*}{$P$ value } \\
\hline & & Range & Mean & SD & Range & Mean & SD & & \\
\hline \multicolumn{2}{|c|}{ Age (yrs) } & $21-39$ & 30.40 & 4.52 & $21-39$ & 30.96 & 4.41 & 1.54 & 0.13 \\
\hline \multicolumn{2}{|c|}{ BMI } & $18.9-35.1$ & 25.73 & 3.86 & $18.8-33.8$ & 25.58 & 3.44 & 0.5 & 0.62 \\
\hline \multirow{2}{*}{\multicolumn{2}{|c|}{ Duration of infertility (yrs) }} & $1-9$ & 3.09 & 1.68 & $1-8$ & 3.20 & 1.64 & 0.81 & 0.42 \\
\hline & & $\mathbf{N}$ & \multicolumn{2}{|c|}{$\%$} & $\mathbf{N}$ & \multicolumn{2}{|c|}{$\%$} & Chi square test & $P$ value \\
\hline \multirow{2}{*}{$\begin{array}{l}\text { Type of } \\
\text { infertility }\end{array}$} & Primary & 204 & \multicolumn{2}{|c|}{$68.0 \%$} & 225 & \multicolumn{2}{|c|}{$75.0 \%$} & & \\
\hline & Secondary & 96 & \multicolumn{2}{|c|}{$32.0 \%$} & 75 & \multicolumn{2}{|c|}{$25.0 \%$} & & \\
\hline & Male factor & 78 & \multicolumn{2}{|c|}{$26.0 \%$} & 78 & \multicolumn{2}{|c|}{$26.0 \%$} & & \\
\hline & PCO & 72 & \multicolumn{2}{|c|}{$24.0 \%$} & 66 & \multicolumn{2}{|c|}{$22.0 \%$} & & \\
\hline \multirow{3}{*}{$\begin{array}{l}\text { Aetiology of } \\
\text { infertility }\end{array}$} & Tubal factor & 60 & \multicolumn{2}{|c|}{$20.0 \%$} & 48 & \multicolumn{2}{|c|}{$16.0 \%$} & 3.84 & 0.43 \\
\hline & Uterine factor & 27 & \multicolumn{2}{|c|}{$9.0 \%$} & 27 & \multicolumn{2}{|c|}{$9.0 \%$} & & \\
\hline & Unexplained & 63 & \multicolumn{2}{|c|}{$21.0 \%$} & 81 & \multicolumn{2}{|c|}{$27.0 \%$} & & \\
\hline
\end{tabular}


The duration and average daily dose of induction was significantly higher in the fasting group than in the non-fasting group. The mean number and percentage of MII oocytes were significantly higher in the fasting group, although there was no significant difference in the total number of oocytes retrieved between the two groups. A significantly higher number of embryos were formed in the fasting group than in the non-fasting group, indicating that the fasting group had a significantly higher number of day 5 transfers and a significantly lower mean number of embryos transferred than the non-fasting group.

The quality of embryos did not differ significantly between the groups. There was no significant difference in the rates of pregnancy or live births either. There was no significant difference in ovarian hyperstimulation between the groups (Table 2).

The frequencies of anxiety and depression were significantly higher in the non-fasting group than in the fasting group $(\mathrm{X} 2=29.82, P<0.00001, \mathrm{X} 2=34.75, P<0.00001)$; this may be related to the spiritual effect of Ramadan in the fasting group (Figure $1 \&$ Figure 2).

The overall pregnancy complication rate among successful patients was higher in the fasting group in comparison to the non-fasting group ( $52.9 \%$ vs. $40.4 \%, P=0.03$ ) (Figure 3 \& Figure 4 ).

Table 2. Comparison between both groups regarding the outcome of IVF/ICSI.

\begin{tabular}{|c|c|c|c|c|c|c|c|c|c|}
\hline & & \multicolumn{3}{|c|}{ Fasting Group (N = 300) } & \multicolumn{3}{|c|}{ Non-Fasting Group (N = 300) } & \multirow{2}{*}{ Student t test } & \multirow{2}{*}{$P$ value } \\
\hline & & Range & Mean & SD & Range & Mean & SD & & \\
\hline \multicolumn{2}{|c|}{ duration of induction(days) } & $9-15$ & 11.89 & 1.21 & $9-14$ & 11.38 & 1.25 & 5.08 & $<0.0001^{*}$ \\
\hline \multicolumn{2}{|c|}{ Dose(international units) } & $225-500$ & 295.25 & 67.58 & $225-450$ & 281.00 & 62.37 & 2.68 & $0.0075^{*}$ \\
\hline \multicolumn{2}{|c|}{ Total oocytes/cycle } & $3-22$ & 11.31 & 3.15 & $4-18$ & 10.84 & 2.78 & 1.94 & 0.06 \\
\hline \multicolumn{2}{|c|}{ M II oocytes/cycle } & $2-18$ & 9.65 & 2.90 & $3-14$ & 8.99 & 2.31 & 3.08 & $0.002^{*}$ \\
\hline \multicolumn{2}{|c|}{ Percent of M II oocytes/cycle } & $0.50-1.0$ & 0.85 & 0.10 & $0.57-1.0$ & 0.83 & 0.09 & 2.57 & $0.01^{*}$ \\
\hline \multicolumn{2}{|c|}{ Embryo number/cycle } & $0-16$ & 8.33 & 2.80 & $2-12$ & 7.55 & 2.09 & 3.87 & $0.0001^{*}$ \\
\hline \multicolumn{2}{|c|}{ Percent of fertilization } & $0.05-1.0$ & 0.85 & 0.12 & $0.50-1.0$ & 0.84 & 0.10 & 1.1 & 0.27 \\
\hline \multirow{2}{*}{\multicolumn{2}{|c|}{ Number of embryos transferred/cycle }} & $2-3$ & 2.12 & 0.33 & $2-3$ & 2.28 & 0.45 & 4.97 & $<0.0001^{*}$ \\
\hline & & $\mathbf{N}$ & \multicolumn{2}{|c|}{$\%$} & $\mathbf{N}$ & \multicolumn{2}{|c|}{$\%$} & Chi square test & $P$ value \\
\hline & A & 198 & \multicolumn{2}{|c|}{$66.7 \%$} & 210 & \multicolumn{2}{|c|}{$70.0 \%$} & & \\
\hline \multirow[t]{3}{*}{ Embryo score } & B & 78 & \multicolumn{2}{|c|}{$26.3 \%$} & 69 & \multicolumn{2}{|c|}{$23.0 \%$} & 0.89 & 0.64 \\
\hline & C & 21 & \multicolumn{2}{|c|}{$7.1 \%$} & 21 & \multicolumn{2}{|c|}{$7.0 \%$} & & \\
\hline & 2.00 & 6 & \multicolumn{2}{|c|}{$2.0 \%$} & 0 & \multicolumn{2}{|c|}{$0.0 \%$} & & \\
\hline \multirow[t]{2}{*}{$\begin{array}{c}\text { Day of } \\
\text { embryo transfer }\end{array}$} & 3.00 & 33 & \multicolumn{2}{|c|}{$11.1 \%$} & 69 & \multicolumn{2}{|c|}{$23.0 \%$} & 20.18 & $<0.00001^{*}$ \\
\hline & 5.00 & 258 & \multicolumn{2}{|c|}{$86.9 \%$} & 231 & \multicolumn{2}{|c|}{$77.0 \%$} & & \\
\hline \multirow{2}{*}{ Pregnancy rate } & Negative & 147 & \multicolumn{2}{|c|}{$49.0 \%$} & 159 & \multicolumn{2}{|c|}{$53.0 \%$} & & \\
\hline & Positive & 153 & 51.0 & & 141 & 47 & & 0.30 & 0.05 \\
\hline \multirow[b]{2}{*}{ Live birth rate } & Negative & 171 & 57.0 & & 180 & 60 & & & \\
\hline & Positive & 129 & 43.0 & & 120 & 40 & & 0.56 & 0.46 \\
\hline Complications of & Negative & 72 & 47.1 & & 84 & 59 & & 461 & $00^{*}$ \\
\hline pregnancy & Positive & 81 & 52.9 & & 57 & 40 & & 4.01 & 0.05 \\
\hline Ovarian & Negative & 282 & 94.0 & & 291 & 97 & & 313 & 008 \\
\hline hyper-stimulation & Positive & 18 & $6.0^{\circ}$ & & 9 & 3. & & 0.10 & 0.00 \\
\hline
\end{tabular}




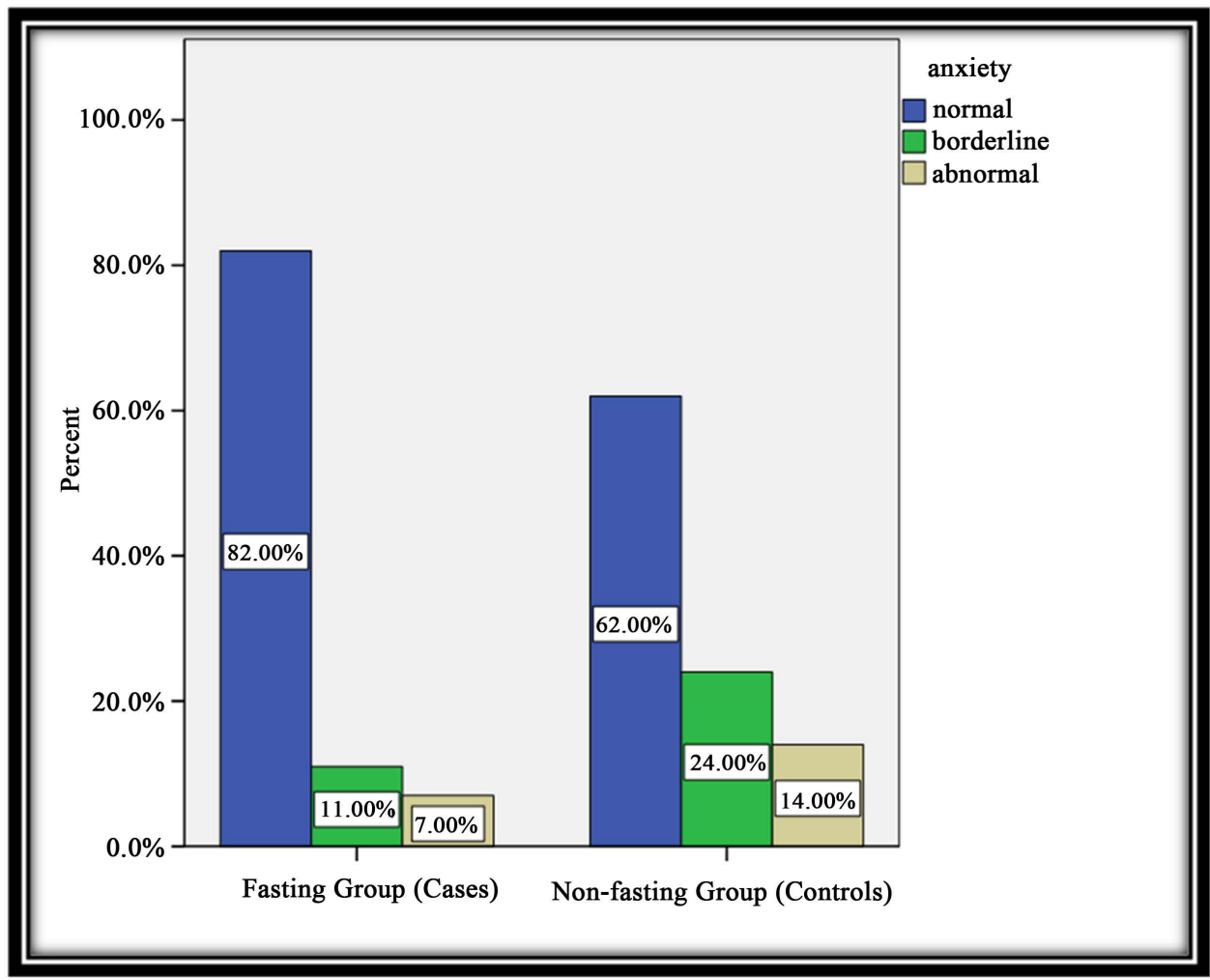

Figure 1. Comparison between both groups regarding the anxiety scale.

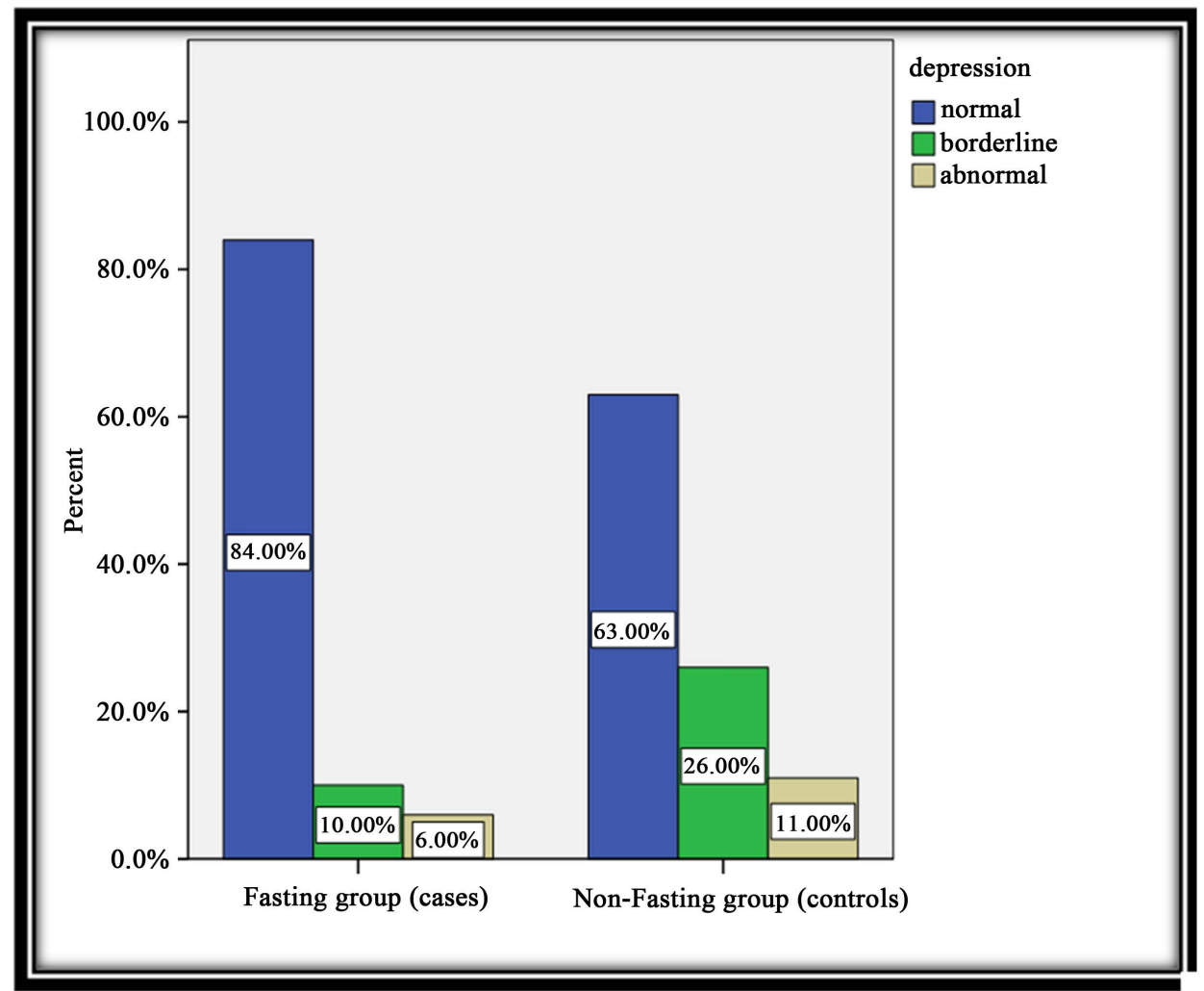

Figure 2. Comparison between both groups regarding the depression scale. 


\section{Complications of pregnancy in the fasting group}

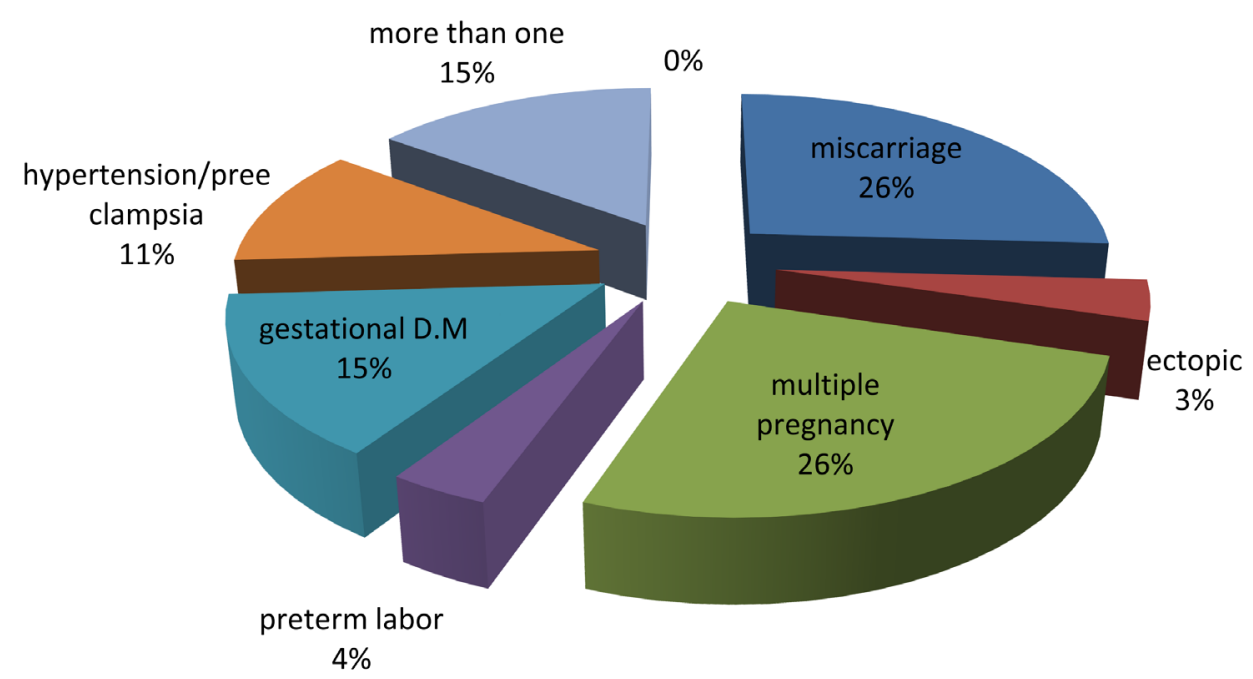

Figure 3. Complications of pregnancy in the fasting group.

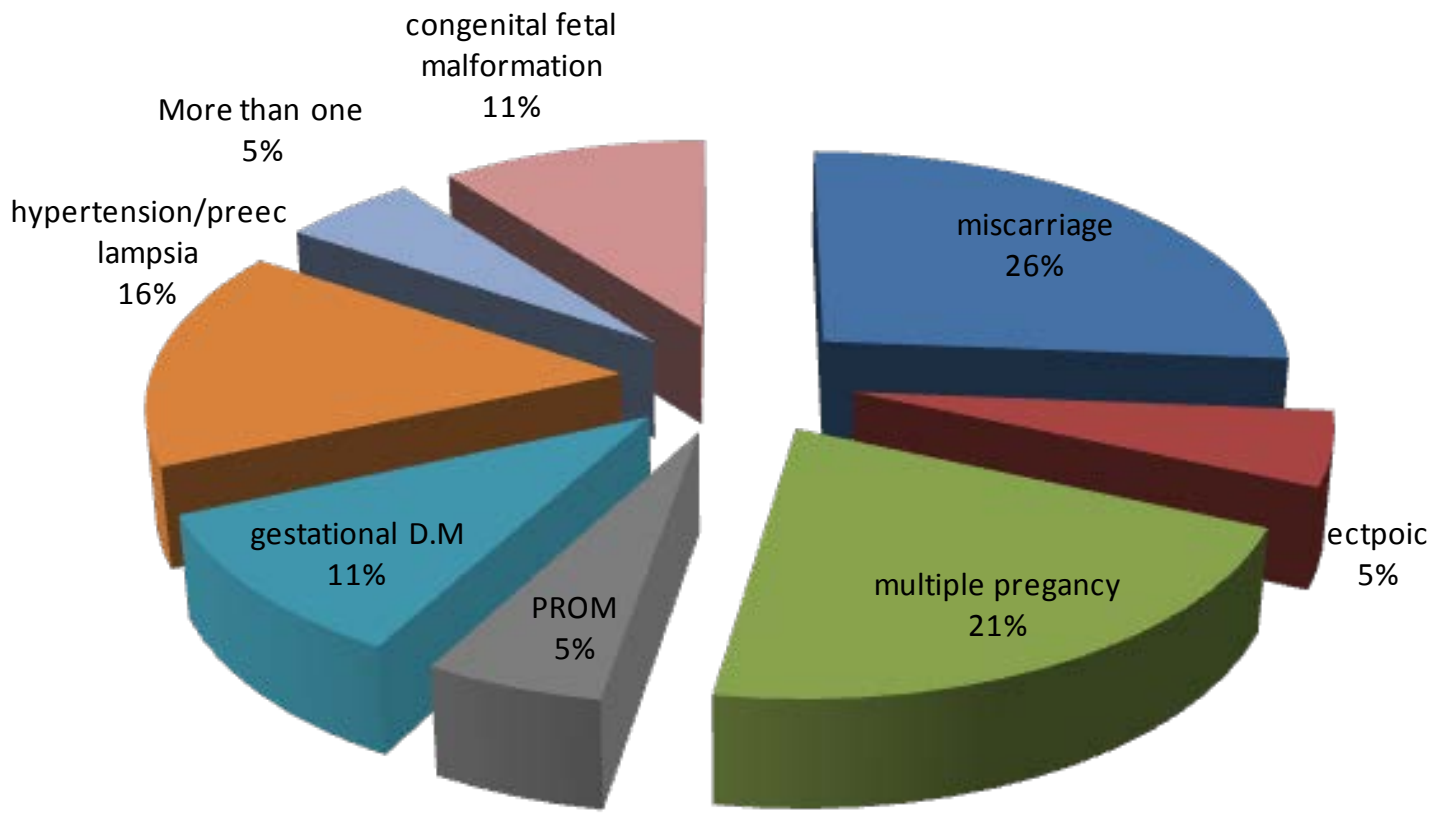

Figure 4. Complications of pregnancy in the non-fasting group.

\section{Discussion}

Fasting during Ramadan is considered one of the five pillars of Islam. It is obligatory for adult Muslims, however those with illnesses, those travelling, pregnant women, women who are breastfeeding, those who are diabetic, and those going through menses are exempted. During this month, there is an increased offering of prayers and recitation of the Quran, and spiritual rewards are believed to be multiplied. Muslims believe that fasting helps a person to strengthen his will, cultivate and refine his taste and manners, strengthen his conviction of doing good, and avoid controversy, petulance, and rashness, all of which contribute towards a healthier personality development.

Many studies have focused on the effect of fasting during Ramadan in pregnancy and on the pregnancy outcome. Most of them did not show any detrimental effects of fasting in healthy women or on the neonatal outcome [16] [17]. Other studies reported that Ramadan fasting during pregnancy might have potential risks [18]. A later study confirmed that menstrual abnormalities, including oligomenorrhoea, polymenorrhoea, and hypermenorrhoea, 
increase during Ramadan, especially in participants who fasted more than 15 days [19].

To our knowledge, no studies have assessed the effect of fasting during Ramadan on IVF/ICSI outcome. Women with infertility experience a greater psychological impact as it significantly reduces the quality of life by increasing anxiety and depression levels [20]. Moreover, women undergoing IVF/ICSI procedures are under severe stress, especially during the waiting period after embryo transfer. Accordingly, investigation of stress reduction methods throughout the IVF cycle is crucial.

Quran recitation and praying are considered to be efficient ways to deepen spirituality and reduce daily stress [21]. Clinicians have found that fasting is frequently accompanied by an increased level of vigilance, mood improvement, a feeling of well-being, and occasionally, a feeling of euphoria. This may be related to several neurobiological mechanisms such as changes in neurotransmitters, quality of sleep, and synthesis of neurotrophic factors [22]. Reduction in anxiety and depression combined with mood improvement are associated with higher rates of success of in vitro fertilization [23].

On the other hand, a well-balanced diet with proper supplementation of vitamins, especially folic acid, and proper hydration is associated with higher live birth rates following assisted reproductive technology treatments [24].

Some patients prefer not to undergo elective medical interventions during the holy month of Ramadan in order to maintain its spiritual theme. Others opt to undergo the medical procedure during that month, in the hope that God will bless this step and increase the chances of success.

Our aim was to investigate whether fasting during Ramadan has any positive or negative impact on the outcome of IVF/ICSI.

In this study, we found that the duration and average daily dose of induction was significantly higher in the fasting group than in the non-fasting group. This might be explained by the lack of food and fluid intake during the fasting hours, which could affect the ovarian response to ovulation-inducing drugs.

The mean number and percentage of MII oocytes were significantly higher in the fasting group, although the total number of oocytes retrieved did not differ between the two groups. A significantly greater number of embryos were formed in the fasting group than in the non-fasting group. This may be explained by the larger number of MII oocytes retrieved in the fasting group, suggesting that day 5 transfers were significantly higher. Hence, the mean number of embryos transferred was significantly lower in the fasting group. There were no significant differences in the quality of the embryos at day 3 or day 5 between the two groups.

Anxiety and depression were significantly lower in the fasting group than in the non-fasting group, which may be related to the spiritual effect of Ramadan. The pregnancy and live birth rates did not differ significantly between the groups. There was no significant difference in ovarian hyperstimulation between the groups. The rate of pregnancy-related complications was significantly higher in the fasting group.

\section{Limitations of the Study}

The current study had some limitations. First, Ramadan, being a lunar month, may occur in any season of the year. The daily fast duration may vary from 10 to 19 hours depending on the season and geographic location. Muslims living closer to the equator experience shorter days, so the effect of fasting may vary depending on the fasting duration. Second, the behavioural response of Muslims around the world to religious requirements is not uniform, and this usually depends on cultural backgrounds and accustomed dietary habits. Another limitation that it would have been better for the study to be conducted as a randomized controlled trial, however, this was not possible considering the religious context to fasting.

\section{Conclusions}

Fasting during the month of Ramadan does not seem to have a significant effect on IVF/ICSI outcome although it significantly reduces anxiety and depression, which may be associated with the procedure.

Multicentre studies on Muslims in various regions of the world need to be considered to have a more global understanding.

\section{Acknowledgements}

I am grateful to all of the patients who agreed to participate in the study. I am also grateful to the whole team of the IVF center in Ain Shams University Maternity hospital for their contribution in this research. 


\section{Competing Interests}

The author of this manuscript has no conflicts of interest with this research.

\section{References}

[1] Bajaj, S., Khan, A., Fathima, F.N., Jaleel, M.A., Sheikh, A., Azad, K., Fatima, J. and Mohsin, F. (2012) South Asian Consensus Statement on Women's Health and Ramadan. Indian Journal of Endocrinology and Metabolism, 16, 508511. http://dx.doi.org/10.4103/2230-8210.97995

[2] Hamdy, E.A., Attia, S. and Ghonna, R. (2008) Effects of the Fast of Ramadan on Endothelial Function and High-Sensitivity C-Reactive Protein in Newly Diagnosed Type 2 Diabetic Patients. The Journal of the Kuwait Medical Association, 40, 53-58.

[3] Emami-Naini, A., Roomizadeh, P., Baradaran, A., Abedini, A. and Abtahi, M. (2013) Ramadan Fasting and Patients with Renal Diseases: A Mini Review of the Literature. Journal of Research in Medical Sciences, 18, 711-716.

[4] Kul, S., Savas, E., Öztürk, Z.A. and Karadag, G. (2014) Does Ramadan Fasting Alter Body Weight and Blood Lipids and Fasting Blood Glucose in a Healthy Population? A Meta-Analysis. Journal of Religion and Health, 53, 929-942. http://dx.doi.org/10.1007/s10943-013-9687-0

[5] Joosoph, J., Abu, J. and Yu, S.L. (2004) A Survey of Fasting during Pregnancy. Singapore Medical Journal, 45, 583586.

[6] Ziaee, V., Razaei, M., Ahmadinejad, Z., et al. (2006) The Changes of Metabolic Profile and Weight during Ramadan Fasting. Singapore Medical Journal, 47, 409-414.

[7] Rahman, M., Rashid, M., Basher, S., et al. (2004) Improved Serum HDL Cholesterol Profile among Bangladeshi Male Students during Ramadan Fasting. Eastern Mediterranean Health Journal, 10, 131-137.

[8] Khoshdel, A., Najafi, M., Kheiri, S., et al. (2007) Impact of Maternal Ramadan Fasting on Growth Parameters in Exclusively Breast-Fed Infants. Iranian Journal of Pediatrics, 17, 345-372.

[9] Salleh, H. (1989) Ramadan Fasting among Pregnant Women in Muar District, Malaysia and Its Association to Health Outcomes. Malaysian Journal of Reproductive Health, 7, 69-83.

[10] Shahgheibi, Sh., Ghadery, E., Pauladi, A., et al. (2005) Effects of Fasting during the Third Trimester of Pregnancy on neonatal Growth Indices. Annals of AlQuds Medicine, 1, 58-62.

[11] Naderi, T. and Kamyabi, Z. (2004) Determination of Final Height Increase in Fasting and Non-Fasting Pregnant Women during Ramadan. Saudi Medical Journal, 25, 809-810.

[12] Boivin, J., Bunting, L., Collins, J.A. and Nygren, K.G. (2007) International Estimates of Infertility Prevalence and Treatment-Seeking: Potential Need and Demand for Infertility Medical Care. Human Reproduction, 22, 1506-1512. http://dx.doi.org/10.1093/humrep/dem046

[13] Prasad, S., Kumar, Y., Singhal, M. and Sharma, S. (2014) Estradiol Level on Day 2 and Day of Trigger: A Potential Predictor of the IVF-ET Success. The Journal of Obstetrics and Gynecology of India, 64, 202-207. http://dx.doi.org/10.1007/s13224-014-0515-6

[14] Zigmond, A.S. and Snaith, R.P. (1983) The Hospital Anxiety and Depression Scale. Acta Psychiatrica Scandinavica, 67, 361-370. http://dx.doi.org/10.1111/j.1600-0447.1983.tb09716.x

[15] Gardner, D.K., Lane, M., Stevens, J., Schlenker, T. and Schoolcraft, W.B. (2000) Blastocyst Score Affects Implantation and Pregnancy Outcome: Towards a Single Blastocyst Transfer. Fertility and Sterility, 73, 1155-1158. http://dx.doi.org/10.1016/S0015-0282(00)00518-5

[16] Awwad, J., Usta, I.M., Succar, J., Musallam, K.M., Ghazeeri, G. and Nassar, A.H. (2012) The Effect of Maternal Fasting during Ramadan on Preterm Delivery: A Prospective Cohort Study. BJOG: An International Journal of Obstetrics \& Gynaecology, 119, 1379-1386. http://dx.doi.org/10.1111/j.1471-0528.2012.03438.x

[17] Ziaee, V., Kihanidoost, Z., Younesian, M., Akhavirad, M.-B., Bateni, F., Kazemianfar, Z. and Hantoushzadeh, S. (2010) The Effect of Ramadan Fasting on Outcome of Pregnancy. Iranian Journal of Pediatrics, 20, 181-186.

[18] Khoshdel, A., Kheiri, S., Hashemi-Dehkordi, E., Nasiri, J., Shabanian-Borujeni, S. and Saedi, E. (2014) The Effect of Ramadan Fasting on LH, FSH, Oestrogen, Progesterone and Leptin in Pregnant Women. Journal of Obstetrics and Gynaecology, 34, 634-638. http://dx.doi.org/10.3109/01443615.2014.920791

[19] Yavangi, M., Amirzargar, M.A., Amirzargar, N. and Dadashpour, M. (2013) Does Ramadan Fasting Has Any Effects on Menstrual Cycles? Iranian Journal of Reproductive Medicine, 11, 145-150.

[20] Kahyaoglu Sut, H. and Balkanli Kaplan, P. (2015) Quality of Life in Women with Infertility via the FertiQoL and the Hospital Anxiety and Depression Scales. Nursing \& Health Sciences, 17, 84-89. http://dx.doi.org/10.1111/nhs.12167

[21] Hematti, S., Baradaran-Ghahfarokhi, M., Khajooei-Fard, R. and Mohammadi-Bertiani, Z. (2015) Spiritual Well-Being 
for Increasing Life Expectancy in Palliative Radiotherapy Patients: A Questionnaire-Based Study. Journal of Religion and Health, 54, 1563-1572. http://dx.doi.org/10.1007/s10943-014-9872-9

[22] Fond, G., Macgregor, A., Leboyer, M. and Michalsen, A. (2013) Fasting in Mood Disorders: Neurobiology and Effectiveness. A Review of the Literature. Psychiatry Research, 209, 253-258. http://dx.doi.org/10.1016/j.psychres.2012.12.018

[23] An, Y., Sun, Z., Li, L., Zhang, Y. and Ji, H. (2013) Relationship between Psychological Stress and Reproductive Outcome in Women Undergoing in Vitro Fertilization Treatment: Psychological and Neurohormonal Assessment. Journal of Assisted Reproduction and Genetics, 30, 35-41. http://dx.doi.org/10.1007/s10815-012-9904-x

[24] Gaskins, A.J., Afeiche, M.C., Wright, D.L., Toth, T.L., Williams, P.L., Gillman, M.W., Hauser, R. and Chavarro, J.E. (2014) Dietary Folate and Reproductive Success among Women Undergoing Assisted Reproduction. Obstetrics \& Gynecology, 124, 801-809. http://dx.doi.org/10.1097/AOG.0000000000000477 